\title{
Parâmetros Biofísicos de Diferentes Tipos de Cobertura do Solo em uma Área de Cerrado no Sul de Mato Grosso
}

\author{
Israel Oliveira Ivo $^{1}$ (D), Marcelo Sacardi Biudes ${ }^{1}$ (D), Nadja Gomes Machado ${ }^{1}$ (D), \\ Luiz Octavio Fabricio dos $\operatorname{Santos}^{1}$ (D), Altemar Lopes Pedreira Junior ${ }^{1}$ \\ ${ }^{1}$ Instituto de Física, Universidade Federal de Mato Grosso, Cuiabá, MT, Brasil.
}

Recebido em: 10 de Junho de 2019 - Revisado em: 3 de Outubro de 2019 - Aceito em: 24 de Outubro de 2019

\begin{abstract}
Resumo
O Cerrado apresenta uma variedade de fitofisionomias, com características distintas em estrutura e distribuição, o que contribui para uma heterogeneidade na interação da radiação solar com a superfície. Dessa forma, o objetivo desse estudo foi avaliar a variabilidade espacial e temporal de parâmetros biofísicos em diferentes tipos de cobertura do solo de uma área de Cerrado no sul do estado de Mato Grosso por sensoriamento remoto. Os parâmetros biofísicos índice de vegetação da diferença normalizada (NDVI), o albedo, temperatura da superfície e o saldo de radiação foram obtidos nas fitofisionomias do Cerrado: Campo Limpo, Campo Sujo, Cerradão e Cerrado stricto sensu; e numa área de pastagem. As estimativas foram realizadas com imagens do sensor TM Landsat 5, em 2009, 2010 e 2011 . No período chuvoso, o NDVI e o saldo de radiação foram $44 \%$ e $15 \%$ maiores e o albedo e a temperatura da superfície foram $18 \%$ e $12 \%$ menores que no seco, respectivamente. Nos locais com maior NDVI e maior saldo de radiação foram encontrados os menores albedo e temperatura da superfície. As diferentes fitofisionomias do Cerrado tiveram interação distinta com a radiação solar em escalas sazonal e espacial devido à variação da cobertura da vegetação e disponibilidade hídrica.
\end{abstract}

Palavras-chave: balanço de radiação, microclima, savana tropical, antropização.

\section{Biophysical parameters of different types of soil cover in a Cerrado area in the south of Mato Grosso}

\begin{abstract}
The Cerrado presents a variety of phytophysiognomies, with distinct characteristics of structure and distribution, which contributes to a heterogeneity in the interaction of solar radiation with the surface. Thus, the objective of this study was to evaluate the spatial and temporal variability of biophysical parameters in different types of soil cover of a Cerrado area in southern Mato Grosso state by remote sensing. Biophysical parameters Normalized Difference Vegetation Index (NDVI), albedo, surface temperature and radiation balance were obtained from the Cerrado phytophysiognomies: Campo Limpo, Campo Sujo, Cerradão and Cerrado stricto sensu; and in a pasture area. Estimates were made with TM Landsat 5 sensor images in 2009, 2010 and 2011. In the rainy season, NDVI and radiation balance were $44 \%$ and $15 \%$ higher and albedo and surface temperature were $18 \%$ and $12 \%$ smaller than dry, respectively. In places with higher NDVI and higher radiation balance, the lowest albedo and surface temperature were found. The different phytophysiognomies of the Cerrado had a distinct interaction with solar radiation at seasonal and spatial scales due to the variation of vegetation cover and water availability.
\end{abstract}

Keywords: radiation balance, microclimate, tropical savanna, anthropization.

\section{Introdução}

A faixa tropical da Terra recebe elevada quantidade de energia solar na sua superfície durante todo o ano. Ao atravessar a atmosfera terrestre, a radiação solar interage com os diversos elementos que a compõem pelos processos de difusão e absorção, o que modifica a sua quantidade e o espectro da radiação solar que atinge a superfície (Barsi et al., 2003). Parte da radiação que atinge a super-

Autor de correspondência: Marcelo Sacardi Biudes, marcelo@fisica.ufmt.br. 
fície volta para a atmosfera pelos processos de reflexão e reemissão de maneira não homogênea, pois os constituintes da superfície interagem de diferentes formas devido ao mosaico de tipos diferentes de cobertura. A contabilização da quantidade de radiação de ondas curtas e longas que atinge e sai da superfície é chamada de saldo de radiação $(R n)$. A interação da radiação de ondas curtas e longas com a superfície e a atmosfera implica em diversos padrões do $R n$ em escalas espacial e temporal (Borges et al., 2010).

A variação espaço-temporal do $R n$ é uma informação fundamental nos estudos de trocas de energia e matéria entre superfície e atmosfera. Em escala microclimática, o $R n$ depende principalmente da cobertura da superfície, em que a densidade de vegetação e a água são os parâmetros que mais o afetam, por meio da regulação da interação entre radiação e superfície (Di Pace et al., 2008; Gomes et al., 2009; Pavão et al., 2015).

O $R n$ pode ser medido diretamente em estações micrometeorológicas com alta precisão. No entanto, essas medidas são pontuais e não expressam a sua variação espacial. Isso pode ser contornado pelos modelos que integram dados medidos em campo e dados de imagens de satélite (Allen et al., 2002; Bastiaanssen et al., 2005). Técnicas de sensoriamento remoto possibilitam não só estimar a variação espacial do $R n$, mas também obter parâmetros biofísicos que auxiliam na caracterização da superfície, como o índice de vegetação da diferença normalizada $(N D V I)$, o albedo da superfície $(\alpha)$ e a temperatura da superfície $\left(T_{s}\right)$ (Fausto et al., 2016).

Localizado na região central da América do Sul, o estado de Mato Grosso recebe elevada quantidade de radiação solar e tem grande variação da disponibilidade de água no solo ao longo do ano, com valores de $7 \%$, a $43 \%$ de umidade do solo e 161 a $203 \mathrm{~W} \mathrm{~m}^{-2}$ de radiação solar média diária (Biudes et al., 2009; 2015). Por se tratar de uma região de transição Cerrado-Pantanal, o Cerrado sul mato-grossense apresenta uma grande diversidade de fitofisionomias, condicionada principalmente pela ocorrência de eventos extremos de inundação e seca e pela variabilidade espacial da fertilidade do solo (Vourlitis et al., 2013). Além disso, diversas áreas de vegetação nativa na região têm sido intensamente substituídas por vegetação exótica, o que modifica significativamente as trocas radiativas e energéticas entre a superfície e a atmosfera (Martins et al., 2015; Fausto et al., 2016).

Os parâmetros biofísicos no Cerrado e no Pantanal mato-grossense apresentam uma variação anual mais acentuada que na Amazônia, principalmente devido à sazonalidade da precipitação e pelo ciclo fenológico dos diferentes tipos vegetacionais (Biudes et al., 2015; Ivo et al., 2018). Muitas espécies de vegetação do Cerrado perdem quase toda a sua folhagem no período seco, refletindo diretamente nos valores dos índices de vegetação, $\alpha, T_{s} \mathrm{e}$ consequentemente no $R n$ superficial (Danelichen et al.,
2014). Além disso, muitas áreas do sul do Cerrado matogrossense são inundadas no período chuvoso, devido à baixa drenagem do solo, modelando a distribuição de espécies na região (Martins et al., 2015; Machado et al., 2016).

A sazonalidade climática, heterogeneidade de solos, disponibilidade hídrica do solo e, consequentemente, a heterogeneidade vegetativa no Cerrado, modificam os parâmetros biofísicos, especialmente o balanço de radiação (Querino et al., 2017; Fausto et al., 2014). A porcentagem de variação dos parâmetros biofísicos, entre os tipos de superfície formados pelas diferentes fitofisionomias do Cerrado alagável é pouco conhecida. Além disso, é necessário estudar dos efeitos de atividades antrópicas na transição Cerrado-Pantanal sobre os parâmetros biofísicos da superfície.

Diante disso, o objetivo desse estudo foi avaliar a variabilidade espacial e temporal de parâmetros biofísicos em diferentes tipos de cobertura do solo de uma área de Cerrado no sul do estado de Mato Grosso por sensoriamento remoto.

\section{Materiais e Métodos}

\section{1 Área experimental}

O estudo foi conduzido em uma área experimental no Cerrado mato-grossense, localizada na Fazenda Miranda $\left(15^{\circ} 43^{\prime} 53,90^{\prime \prime} \mathrm{S}, 56^{\circ} 4^{\prime} 20,50^{\prime \prime} \mathrm{O}\right)$, a $181 \mathrm{~m}$ acima do nível do mar e a $15 \mathrm{~km}$ do município de Cuiabá (Fig. 1A). O clima local é classificado como Aw, segundo Köppen, com temperatura e precipitação média anual entre $22 \mathrm{e}$ $25^{\circ} \mathrm{C}$ e $1335 \mathrm{~mm}$, respectivamente, com período chuvoso entre outubro e abril e período seco entre maio e setembro (Marcuzzo \& Melo, 2011; Machado et al., 2016). O solo da área de estudo é LATOSSOLO vermelho-amarelo distrófico, rochoso (Biudes et al., 2009; Biudes et al., 2015).

Foram selecionados cinco pontos em diferentes tipos de cobertura da superfície (Fig. 1B):1) Campo Limpo (CLI) $\left(15^{\circ} 43^{\prime} 53,90^{\prime \prime} \mathrm{S}, 56^{\circ} 4^{\prime} 20,50^{\prime \prime} \mathrm{O}\right)$, localizado em uma área de vegetação nativa rasteira, com gramíneas e arbustos em baixa densidade, onde foi instalada uma torre micrometeorológica de $20 \mathrm{~m}$; 2) Pastagem (PAS) $\left(15^{\circ}\right.$ $\left.44^{\prime} 0,42^{\prime \prime} \mathrm{S}, 56^{\circ} 4^{\prime} 39,58^{\prime \prime} \mathrm{O}\right)$, localizado em uma área de pastagem; 3) Campo Sujo (CSU) $\left(15^{\circ} 43^{\prime} 30.53^{\prime \prime} \mathrm{S}, 56^{\circ}\right.$ 4'20.53"O), localizado em uma área densamente composta por vegetação arbustiva, gramíneas e árvores de pequeno porte $(4-6 \mathrm{~m})$; 4) Cerradão $(\mathrm{CAO})\left(15^{\circ}\right.$ 43’42,36"S, 56 4’40,87"O), localizado em uma área de floresta nativa, com predominância de árvores de grande porte $(8-10 \mathrm{~m}) ; 5)$ Cerrado stricto sensu (CER) $\left(15^{\circ}\right.$ $\left.44^{\prime} 8,20^{\prime \prime} \mathrm{S}, 56^{\circ} 4^{\prime} 36,00^{\prime \prime} \mathrm{O}\right)$, localizado em uma área de vegetação arbórea, com o dossel mais curto e aberto do que no Cerradão (Vourlitis et al., 2013). 


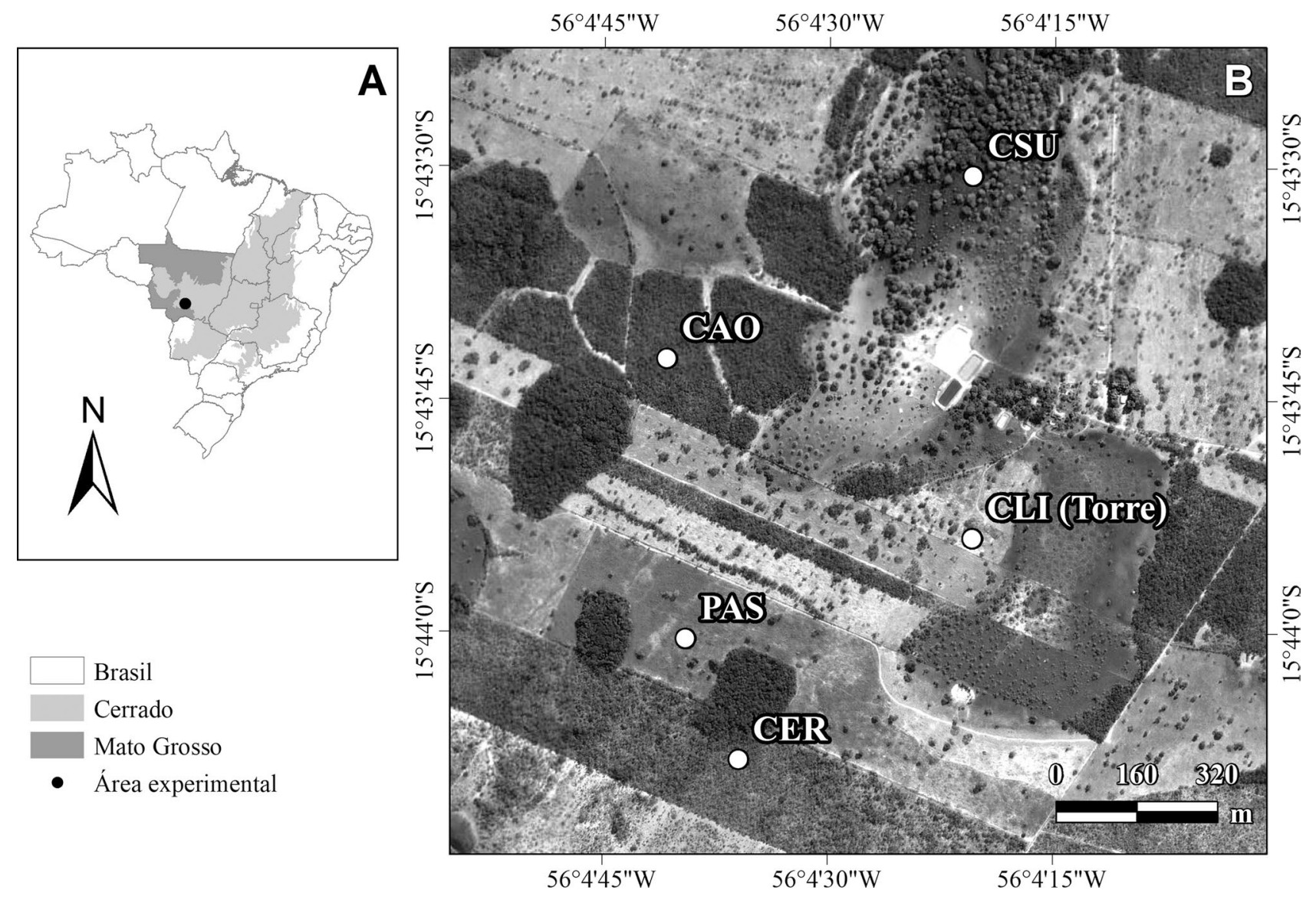

Figura 1 - Localização da área experimental e da Torre micrometeorológica no Cerrado Mato-Grossense e diferentes tipos de cobertura da superfície, em Campo Limpo (CLI), Pastagem (PAS), Campo Sujo (CSU), Cerradão (CAO) e em cerrado stricto sensu (CER), na Fazenda Miranda.

\subsection{Dados micrometeorológicos medidos}

O saldo de radiação $(R n)$, radiação solar global $(R g)$, Temperatura $\left(T_{a r}\right)$ e Umidade Relativa $(U R)$ do ar foram medidos por sensores instalados na torre micrometeorológica na área de estudo (Fig. 1B) entre janeiro de 2009 e dezembro de 2011. O Rn foi medido por um saldo radiômetro (NRLITE, Kipp \& Zonen, Delft, Netherlands), a Rg por um piranômetro (LI200X, LI-COR, Lincoln, NE, USA) e a $T_{a r}$ e $U R$ foram medidas por um termohigrômetro (HMP-45AC, Vaisala Inc., Woburn, MA, USA) instalados a $5 \mathrm{~m}$ do solo. Os sensores foram calibrados em um intervalo mínimo de seis meses ao longo do período da coleta, o que garantiu uma maior acuracidade dos dados medidos, sendo que o recomendado pelo fabricante é calibrar os sensores a cada dois anos.

\subsection{Precipitação}

A precipitação mensal na área de estudo foi obtida do produto 3B43 V7 do satélite TRMM (Tropical Rainfall Measuring Mission) da Plataforma Giovanni da National Aeronautics and Space Administration (NASA) (Danelichen et al., 2013).
Foram utilizados dados da normal climatológica da precipitação mensal no município de Cuiabá-MT para avaliar os valores da precipitação entre janeiro de 2009 e dezembro de 2011 (INMET, 2018).

\subsection{Dados orbitais}

Foram obtidos dados de refletância da superfície e a temperatura de brilho da área experimental, por meio de imagens do sensor Thematic Mapper (TM) Landsat 5 da órbita 226 e ponto 71 . Essas imagens foram obtidas gratuitamente da plataforma Center Science Processing Architeture (ESPA, espa.cr.usgs.gov) do Serviço Geológico Americano (USGS). Somente imagens sem a presença de nuvens foram obtidas. As imagens de refletância da superfície passaram por correções radiométrica, atmosférica, geométrica sistemática e de precisão, e erro paralaxe pelo modelo digital pela plataforma ESPA-USGS. Foram selecionadas duas imagens por ano, uma no período seco e outra no período chuvoso, correspondentes as datas 16/04 e $07 / 09$ de $2009,18 / 03$ e $24 / 07$ de $2010,22 / 04$ e 29/09 de 2011.

Primeiramente, foi realizada a composição das bandas espectrais $1,2,3,4,5,7$ e a temperatura de brilho 
(banda 6). Em seguida, as imagens da área de estudo foram recortadas. Posteriormente, foram calculados o $\alpha$, NDVI, $T_{s}, R n$ (Fig. 2), descritos abaixo.

\subsection{Saldo de radiação}

$\mathrm{O}$ saldo de radiação $\left(R n ; \mathrm{W} \mathrm{m}^{-2}\right)$ foi calculado pela Eq. (1) (Allen et al., 2002).

$$
R n=R g(1-\alpha)-R_{L \uparrow}+R_{L \downarrow}-\left(1-\varepsilon_{0}\right) R_{L \downarrow}
$$

em que $R g$ é a radiação solar global $\left(\mathrm{W} \mathrm{m}^{-2}\right), \alpha$ é o albedo da superfície em cada pixel (Eq. (2)), $\varepsilon_{0}$ é a emissividade da superfície de cada pixel, $R_{L \downarrow}$ é a radiação de onda longa emitida pela atmosfera que chega à superfície correspondente a cada pixel $\left(\mathrm{W} \mathrm{m}^{-2}\right), R_{L \uparrow}$ é a radiação de onda longa emitida pela superfície correspondente a cada pixel $\left(\mathrm{W} \mathrm{m}^{-2}\right)$.

$$
\begin{array}{r}
\alpha=0,356 \rho_{1}+0,13 \rho_{3}+0,373 \rho_{4} \\
+0,085 \rho_{5}+0,072 \rho_{7}-0,0018
\end{array}
$$

em que $\rho_{1}, \rho_{3}, \rho_{4}, \rho_{5}$ e $\rho_{7}$ são as refletâncias da superfície das bandas 1, 3, 4, 5 e 7 do sensor TM-Landsat 5 (Liang et al., 2002).

A radiação de onda longa emitida pela atmosfera e emitida pela superfície são calculadas pela Eq. de StefanBoltzmann (Eqs. (3) e (4)) (Allen et al., 2002).

$$
\begin{aligned}
& R_{L \uparrow}=\varepsilon_{0} \sigma T_{s}^{4} \\
& R_{L \uparrow}=\varepsilon_{0} \sigma T_{a r}^{4}
\end{aligned}
$$

em que $\varepsilon_{a}$ é a emissividade da atmosfera de cada pixel e $\sigma$ é a constante de Stefan-Boltzman $\left(\sigma=5,67 \times 10^{-8} \mathrm{Wm}^{-2} \mathrm{~K}^{-4}\right)$, $T_{a r}$ e $T_{s}$ são as temperaturas do ar e da superfície $(\mathrm{K})$, respectivamente.
A $\varepsilon_{0}$ em cada pixel foi calculada através da Eq. (5) baseado no modelo de cobertura da vegetação (Valor \& Caselles, 1996).

$$
\begin{array}{r}
\varepsilon_{0}=\varepsilon_{v} P_{v}+\varepsilon_{g}\left(1-P_{v}\right)\left(1-1,74 P_{v}\right) \\
+1,7372 P_{v}\left(1-P_{v}\right)
\end{array}
$$

em que $\varepsilon_{v}$ e $\varepsilon_{g}$ são as emissividades da vegetação e do solo puro, cujos valores utilizados são 0,985 e 0,960 , respectivamente. $P_{v}$ é a fração de cobertura da vegetação calculada pela Eq. (6) em função do NDVI (Eq. (7)).

$$
\begin{gathered}
P_{v}=\left[\frac{\left(N D V I-N D V I_{\min }\right)}{\left(N D V I_{\max }-N D V I_{\min }\right)}\right]^{2} \\
N D V I=\frac{\rho_{4}-\rho_{3}}{\rho_{4}+\rho_{3}}
\end{gathered}
$$

em que $N D V I_{\max }$ e $N D V I_{\min }$ são os valores de $N D V I$ máximos e mínimos, respectivamente.

A emissividade da atmosfera foi calculada pela Eq. (8) (Idso, 1981).

$$
\varepsilon_{a r}=0,7+5,95 \times 10^{-7} e_{a r} \exp \left(\frac{1500}{T_{a r}-273,15}\right)
$$

em que $e_{a r}$ é a pressão de vapor do ar e $T_{a r}$ é a temperatura do $\operatorname{ar}(\mathrm{K})$.

A temperatura da superfície $\left(T_{S}\right)$ foi calculada pela Eq. (9).

$$
T_{\text {sup }}=\frac{k_{2}}{\ln \left(\frac{k_{1}}{L_{T}}+1\right)}
$$

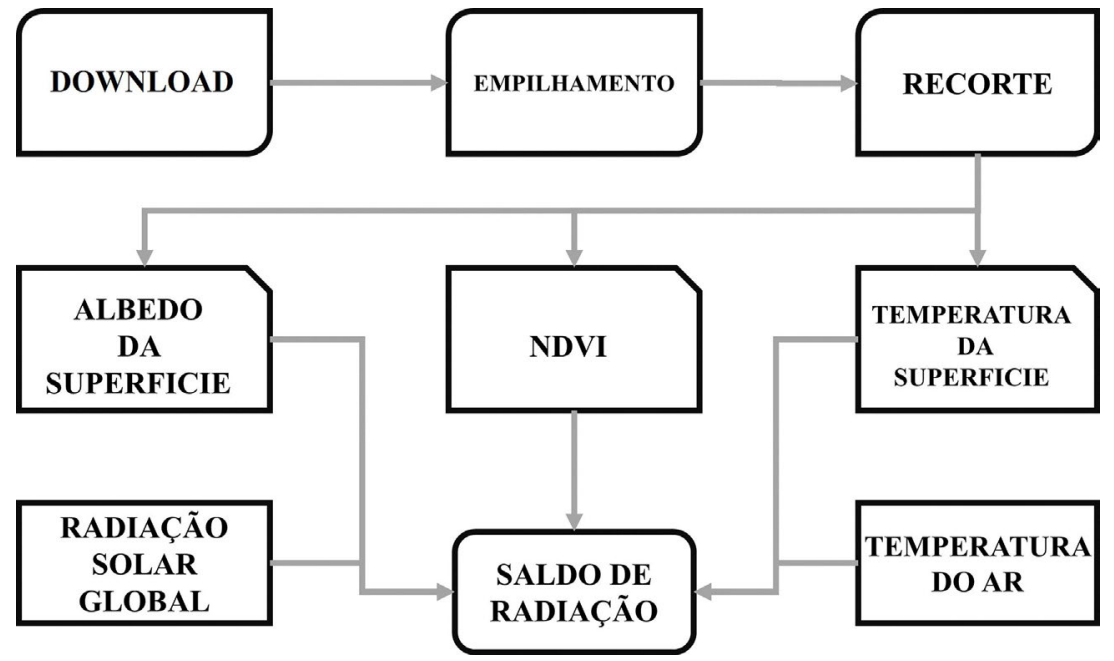

Figura 2 - Fluxograma das etapas do processamento dos dados orbitais e meteorológicos para estimar o saldo de radiação da superfície. 
em que $k_{1}=607,76 \mathrm{~W} \mathrm{~m}^{-2} \mathrm{sr}^{-1} \mu \mathrm{m}^{-1}$ e $k_{2}=1260,56 \mathrm{~K}$ são constantes e $L_{T}$ é a radiância espectral da banda termal corrigida para os efeitos da atmosfera $\left(\mathrm{W} \mathrm{m}^{-2} \mu \mathrm{m}^{4} \mathrm{sr}^{-1}\right)$, calculada pela Eq. (10).

$$
L_{T}=\frac{L_{T O A}-\tau\left(1-\varepsilon_{0}\right) L_{d}-L_{u}}{\tau \varepsilon_{0}}
$$

em que $L_{T O A}$ é a radiância térmica emitida pela superfície (Eq. $11 ; \mathrm{W} \mathrm{m}^{-2} \mu \mathrm{m}^{4} \mathrm{sr}^{-1}$ ), $\tau$ é a transmitância atmosférica, $L_{d}$ é a radiância ressonante efetiva descendente na banda termal $\left(\mathrm{W} \mathrm{m}^{-2} \mu \mathrm{m}^{4} \mathrm{sr}^{-1}\right)$ e $L_{u}$ é a radiância ressonante efetiva ascendente na banda termal $\left(\mathrm{W} \mathrm{m}^{-2} \mu \mathrm{m}^{4} \mathrm{sr}^{-1}\right)$. Os valores de $\tau, L_{u}$ e $L_{d}$ (Tabela 1) foram obtidos na plataforma Atmospheric Correction Parameter Calculator, desenvolvido pela North National Aeronautics and Space Administration (NASA, atmcorr.gsfc.nasa.gov) (Barsi et al., 2005).

$$
L_{T O A}=\frac{C_{1}}{\lambda^{5}\left(e^{\frac{C_{2}}{\lambda\left(\rho_{6} \times 0,1\right)}}-1\right)}
$$

em que $\lambda=11,475$ é o centro de onda, $C_{I}=1,19104356$ $\times 108 \mathrm{~W} \mu \mathrm{m}^{4} \mathrm{~m}^{-2} \mathrm{sr}^{-1}$ e $C_{2}=1,4387685 \times 104 \mu \mathrm{m} \mathrm{K}$ são constantes e $\rho_{6}$ é a refletância da banda 6 do sensor TMLandsat 5.

\subsection{Análises estatísticas}

Foi selecionado um pixel, denominado de "pixels central", em CLI, CSU, PAS, CAO e CER, sobre cada imagem temática. Além disso, sobre cada imagem temática, foram adicionados mais oito pixels em torno de cada pixel central, totalizando nove pixels em cada ponto. Por fim, foram calculadas médias e respectivos intervalos de confiança dos valores extraídos, pelo método bootstraping, com mil reamostragens, em CLI, CSU, PAS, CAO e CER, nas imagens temáticas (Efron \& Tibshirani, 1993).

As estimativas do $N D V I, \alpha, T_{s}$ e $R n$ foram correlacionadas por meio da análise do correlograma, utilizando o método de Spearman, no sotware R, pacote "PerformanceAnalytics" (Peterson \& Carl, 2018).
A análise do modelo foi realizada com base nos valores estimados do $R n$ na coordenada correspondente à localização da torre micrometeorológica (CLI) em função dos dados medidos. Dessa forma, o desempenho do modelo foi avaliado considerando os valores calculados da Raiz do Erro Quadrático Médio (REQM), do Erro Médio Absoluto (EMA), do Erro Percentual Relativo Médio (EPRM), do índice de concordância de Willmott $(d)$ e do coeficiente de correlação de Spearman $(r)$.

O REQM foi calculado pela Eq. (12), e indica o quanto o modelo erra em estimar a variabilidade das medidas em torno da média e mede a variação dos valores estimados ao redor dos valores medidos. O menor limite em $R E Q M$ é zero, indicando que há plena adesão entre as estimativas do modelo e os dados medidos.

$$
R E Q M=\sqrt{\frac{\sum\left(P_{i}-O_{i}\right)^{2}}{n}}
$$

em que $P_{i}$ são os valores estimados, $O_{i}$ são os valores medidos e $n$ é o número total de amostras.

Os EMA e o EPRM, calculados através das Eqs. (13) e (14), indicam o desvio médio absoluto e o erro percentual dos valores estimados em relação aos valores medidos, respectivamente. Um caso ideal ocorre quando os valores do EMA e o EPRM são iguais a zero (Danelichen et al., 2014).

$$
\begin{gathered}
E M A=\sum \frac{\left|P_{i}-O_{i}\right|}{n} \\
E P R M=\frac{100}{n} \sum\left|\frac{P_{i}-O_{i}}{O_{i}}\right|
\end{gathered}
$$

$\mathrm{O} d$ foi calculado de acordo com a Eq. (15) (Willmott et al., 1985). Os valores de $d$ variam entre 0 e 1 indicando não concordância e concordância perfeita, respectivamente. Analogamente os valores do $r$ variam de 0 a 1 , indicando nenhuma correlação ou correlação perfeita, respectivamente (Machado et al., 2016).

$$
d=1-\frac{\sum\left(P_{i}-O_{i}\right)}{\sum\left(\left|O_{i}-\bar{P}\right|+\left|P_{i}-\bar{P}\right|\right)^{2}}
$$

Tabela 1 - Transmitância atmosférica $(\tau)$, radiância ressonante efetiva descendente, $L_{d}\left(\mathrm{~W} \mathrm{~m}^{-2} \mathrm{sr}^{-1} \mu \mathrm{m}^{-1}\right)$, e radiância ressonante efetiva ascendente, $L_{u}$ (W $\left.\mathrm{m}^{-2} \mathrm{sr}^{-1} \mu \mathrm{m}^{-1}\right)$, para as datas correspondentes, na Fazenda Miranda.

\begin{tabular}{lccc}
\hline Data & $L_{d}$ & $L_{u}$ & $\tau$ \\
\hline $16 / 04 / 2009$ & 6,96 & 4,97 & 0,38 \\
$07 / 09 / 2009$ & 6,8 & 4,7 & 0,43 \\
$18 / 03 / 2010$ & 7,0 & 4,92 & 0,39 \\
$24 / 07 / 2010$ & 5,49 & 3,75 & 0,55 \\
$22 / 04 / 2011$ & 6,49 & 4,52 & 0,45 \\
$29 / 09 / 2011$ & 5,89 & 3,91 & 0,52 \\
\hline
\end{tabular}




\section{Resultados e Discussão}

\subsection{Precipitação}

Foi identificado um padrão sazonal de precipitação semelhante ao previsto pela normal climatológica do município de Cuiabá-MT. Contudo, a precipitação foi $32 \mathrm{~mm}$ menor no período seco e $218 \mathrm{~mm}$ maior no período chuvoso que a normal climatológica (Fig. 3). A precipitação mensal acumulada foi próxima aos valores previstos pela normal climatológica de Cuiabá-MT, porém houve registros de anomalias acima de $100 \mathrm{~mm}$ em alguns meses de 2011 (Fig. 3). Os maiores valores de precipitação mensal foram obtidos em fevereiro e março e os menores entre junho a agosto.

As anomalias na precipitação estão relacionadas aos eventos causados pelos deslocamentos da Zona de Convergência Intertropical (ZCIT) e Zona de Convergência do Atlântico Sul (ZCAS) para regiões fora de sua posição normal, em contrapartida com as flutuações da temperatura superficial do oceano pacífico sul, além do enfraquecimento dos ventos alísios neste período. Estas anomalias térmicas no pacífico sul estabeleceram condições de El Niño (2009 a 2010) e La Niña (2010 a 2011) que em consistência com os deslocamento relativos das ZCAS e ZCIT foram os principais fatores na dinâmica do regime de chuvas na região da área experimental (INMET, 2009-2011, inmet.gov.br; SIPAM 2009-2011, sipam.gov.br).

\subsection{Análise dos parâmetros biofísicos}

Os valores do $N D V I$ foram afetados pela precipitação $(r=0,71)$ e pelo padrão de cobertura da superfície. Isso é esperado, pois o NDVI é uma medida indireta da disponibilidade de água no solo (Danelichen et al., 2016).
O NDVI no período seco foi $31 \%$ menor que no período chuvoso (Fig. 4; Tabela 2). As áreas de vegetação nativas CER e CAO apresentaram variações acentuadas do $N D V I$, com valores que corroboram aos resultados obtidos em outros locais de cerrado (Fig. 4) (Martins et al., 2015). Os maiores valores de $N D V I$ foram observados no CAO e menores na PAS. O NDVI em PAS foi $32 \%, 27 \%$ e $9 \%$ menor que no CAO, CLI e CSU, respectivamente. O NDVI no CER não diferiu significativamente ao do CAO (Tabela 2).

O padrão do $N D V I$ da área de estudo corroborou com os obtidos em outros estudos, que observaram maiores valores de $N D V I$ em locais com maior biomassa vegetal e em períodos cuja disponibilidade hídrica no perfil do solo é abundante. Estudo realizado no perímetro irrigado de Gorutuba-MG identificou $N D V I$ em área de vegetação nativa entre 0,70 e 0,94 durante o período chuvoso e entre 0,48 e 0,81 no período seco (Boratto \& Gomide, 2013). Em estudo realizado no Cerrado Mato-Grossense, avaliando os impactos da mudança do uso e cobertura do solo, foi identificado que o NDVI em área de vegetação nativa do Cerrado foi $40 \%$ maior do que em pastagem (Fausto et al., 2016).

$\mathrm{O} \alpha$ foi inversamente proporcional ao $N D V I$ (Fig. $5 \mathrm{e}$ 7). O $\alpha$ no período seco foi $22 \%$ maior que no período chuvoso (Fig. 5). Os diferentes tipos de cobertura da superfície tiveram valores de $\alpha$ distintos (Fig. 5; Tabela 2). $\mathrm{O} \alpha$ na PAS e no CLI foi $16 \%$ e $4 \%$ maior que no CAO, respectivamente, e o $\alpha$ no CSU foi $22 \%$ menor que no CAO. O $\alpha$ no CER não diferiu significativamente ao do CAO (Tabela 2).

A variação da cobertura da vegetação modifica as propriedades espectrais da superfície e a capacidade da captura da radiação solar (Fausto et al., 2016). A baixa cobertura da vegetação aumenta a exposição do solo à ra-

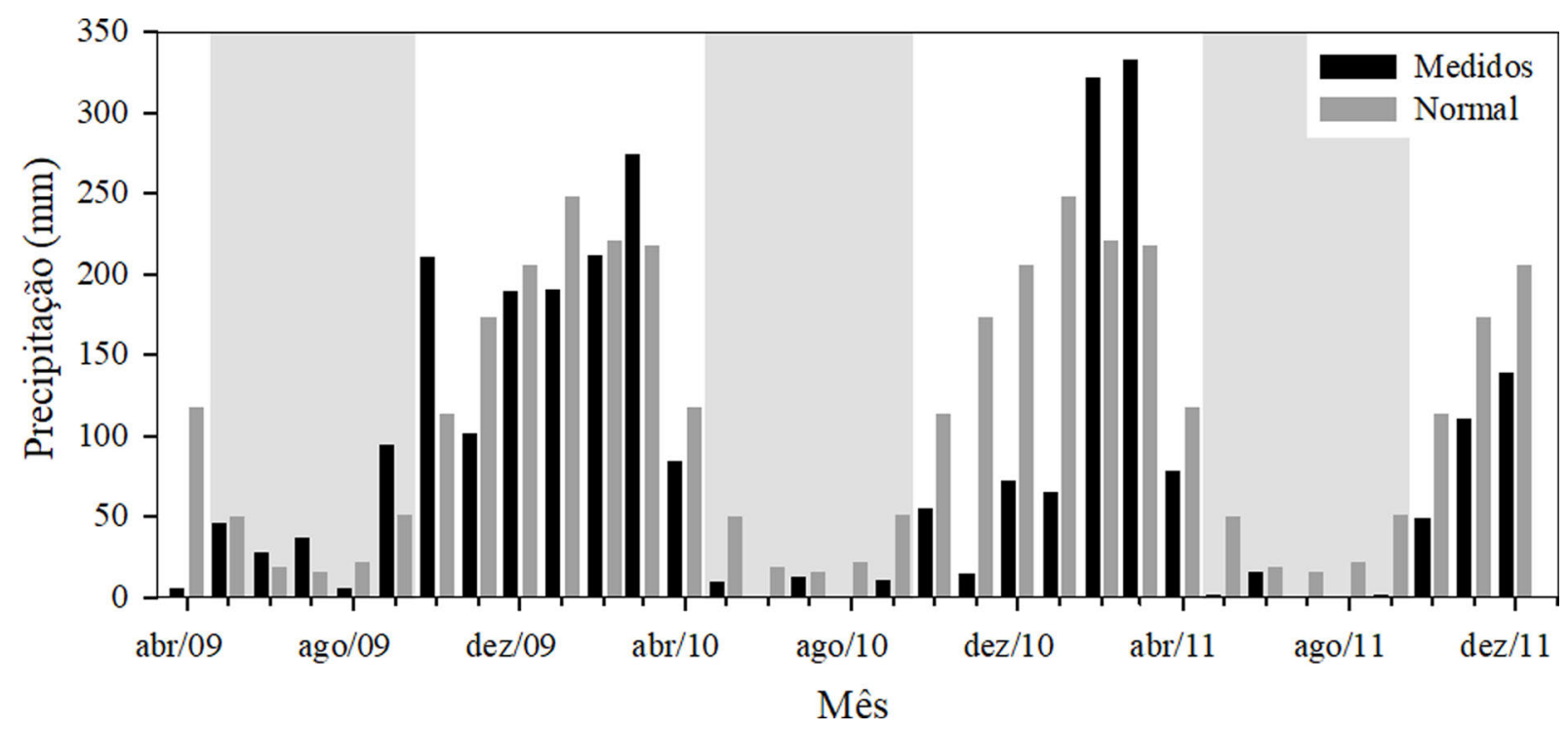

Figura 3 - Precipitação mensal entre 2009 e 2011 na Fazenda Miranda e da normal climatológica de Cuiabá-MT. Área em cinza representa o período seco na região. 

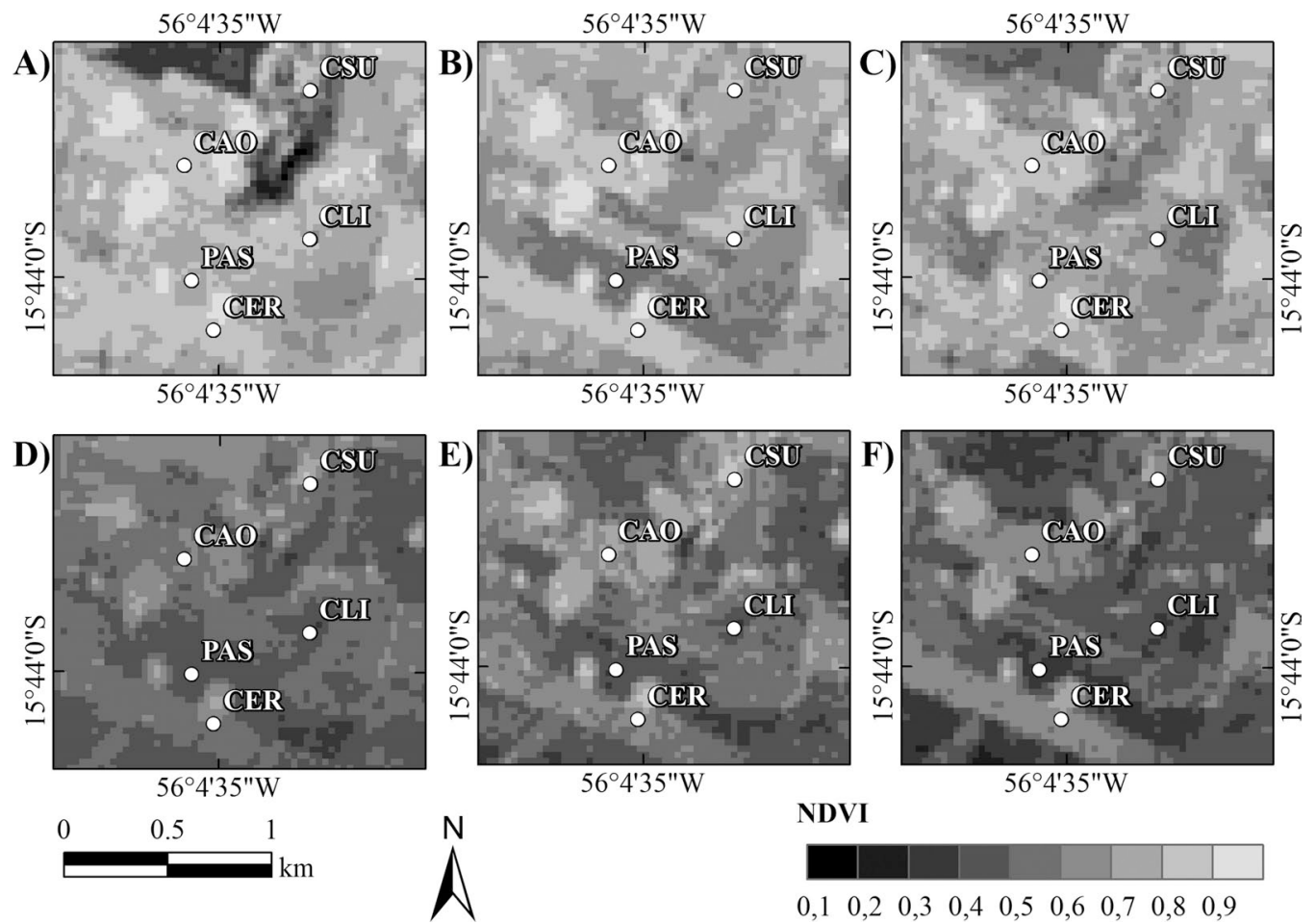

Figura 4 - Distribuição espacial do Índice de Vegetação da Diferença Normalizada (NDVI) em Campo Limpo (CLI), Pastagem (PAS), Campo Sujo (CSU), Cerradão (CAO) e em Cerrado stricto sensu (CER), no período chuvoso (A, B e C) e período seco (D, E e F), na Fazenda Miranda, em 2009,2010 e 2011.

Tabela 2 - Médias \pm intervalo de confiança dos parâmetros biofísicos para os períodos seco (Seco) e chuvoso (Chuv.) em cerrado stricto sensu (CER), Cerradão (CAO), Campo Limpo (CLI), Campo Sujo (CSU), e em Pastagem (PAS) na Fazenda Miranda, de 2009 a 2011.

\begin{tabular}{|c|c|c|c|c|c|}
\hline Local & Período & NDVI & $\alpha_{\text {sup }}(\%)$ & $\mathrm{T}_{\text {sup }}\left({ }^{\circ} \mathrm{C}\right)$ & $\operatorname{Rn}\left(\mathrm{Wm}^{-2}\right)$ \\
\hline \multirow[t]{2}{*}{ CER } & Chuv. & $0,73 \pm 0,01$ & $11,7 \pm 0,33$ & $33,21 \pm 0,56$ & $503,2 \pm 9,5$ \\
\hline & Seco & $0,52 \pm 0,01$ & $13,86 \pm 0,53$ & $37,01 \pm 1,15$ & $447,2 \pm 18,5$ \\
\hline \multirow[t]{2}{*}{$\mathrm{CAO}$} & Chuv. & $0,76 \pm 01$ & $12 \pm 0,22$ & $31,67 \pm 0,44$ & $510,9 \pm 10,8$ \\
\hline & Seco & $0,55 \pm 0,01$ & $13,92 \pm 0,6$ & $35,82 \pm 1,27$ & $454,35 \pm 17,65$ \\
\hline \multirow[t]{2}{*}{ CLI } & Chuv. & $0,62 \pm 0,02$ & $14,01 \pm 0,28$ & $35,63 \pm 0,7$ & $472,65 \pm 8,85$ \\
\hline & Seco & $0,34 \pm 0,01$ & $15,7 \pm 0,88$ & $42,44 \pm 2,19$ & $399,35 \pm 9,44$ \\
\hline \multirow[t]{2}{*}{$\mathrm{CSU}$} & Chuv. & $0,63 \pm 0,03$ & $7,27 \pm 0,67$ & $31,96 \pm 0,4$ & $539,8 \pm 9,8$ \\
\hline & Seco & $0,56 \pm 0,04$ & $12,95 \pm 1,45$ & $35,77 \pm 2,52$ & $459,45 \pm 5,84$ \\
\hline \multirow[t]{2}{*}{ PAS } & Chuv. & $0,58 \pm 0,03$ & $14,15 \pm 0,21$ & $34,73 \pm 0,79$ & $477,1 \pm 10,3$ \\
\hline & Seco & $0,32 \pm 0,01$ & $16,21 \pm 0,85$ & $40,36 \pm 1,49$ & $411,7 \pm 13,7$ \\
\hline
\end{tabular}

diação solar, que possui maior $\alpha$ (Martins et al., 2015). Dessa forma, a disponibilidade de água na superfície influencia na dinâmica da vegetação, e consequentemente, altera o $\alpha$ (Sallo et al., 2014).

Em estudo realizado no Cerrado no sul de Mato Grosso, foram identificadas médias do $\alpha$ em área de floresta nativa de $15 \%$ e na pastagem $22 \%$ (Fausto et al., 2016). Em outro estudo, também realizado em área de Cerrado, no município de Campo Novo do Parecis-MT, foram identificados valores médios do $\alpha$ em uma área de vegetação nativa legal de $8 \%$ e em uma área desmatada de
13\% (Martins et al., 2015). Fausto et al., (2014) identificaram que em média, o $\alpha$ em áreas de pastagem foi $27 \%$ maior que em área de mata nativa no período chuvoso e $43 \%$ no período seco, o que evidencia a dependência do albedo às condições hídricas da superfície.

A $T_{s}$ variou entre $31^{\circ} \mathrm{C}$ e $39^{\circ} \mathrm{C}$ no período chuvoso e entre $29^{\circ} \mathrm{C}$ e $51^{\circ} \mathrm{C}$ no período seco (Fig. 6). A $T_{s}$ no período seco foi em média $14 \%$ maior que no período chuvoso (Tabela 2). A $T_{s}$ correlacionou negativamente com o NDVI e positivamente com o $\alpha$ (Fig. 7), i.e., a cobertura da vegetação interferiu na $T_{s}$. A $T_{s}$ na PAS e no CLI foi $11 \%$ e $16 \%$ 

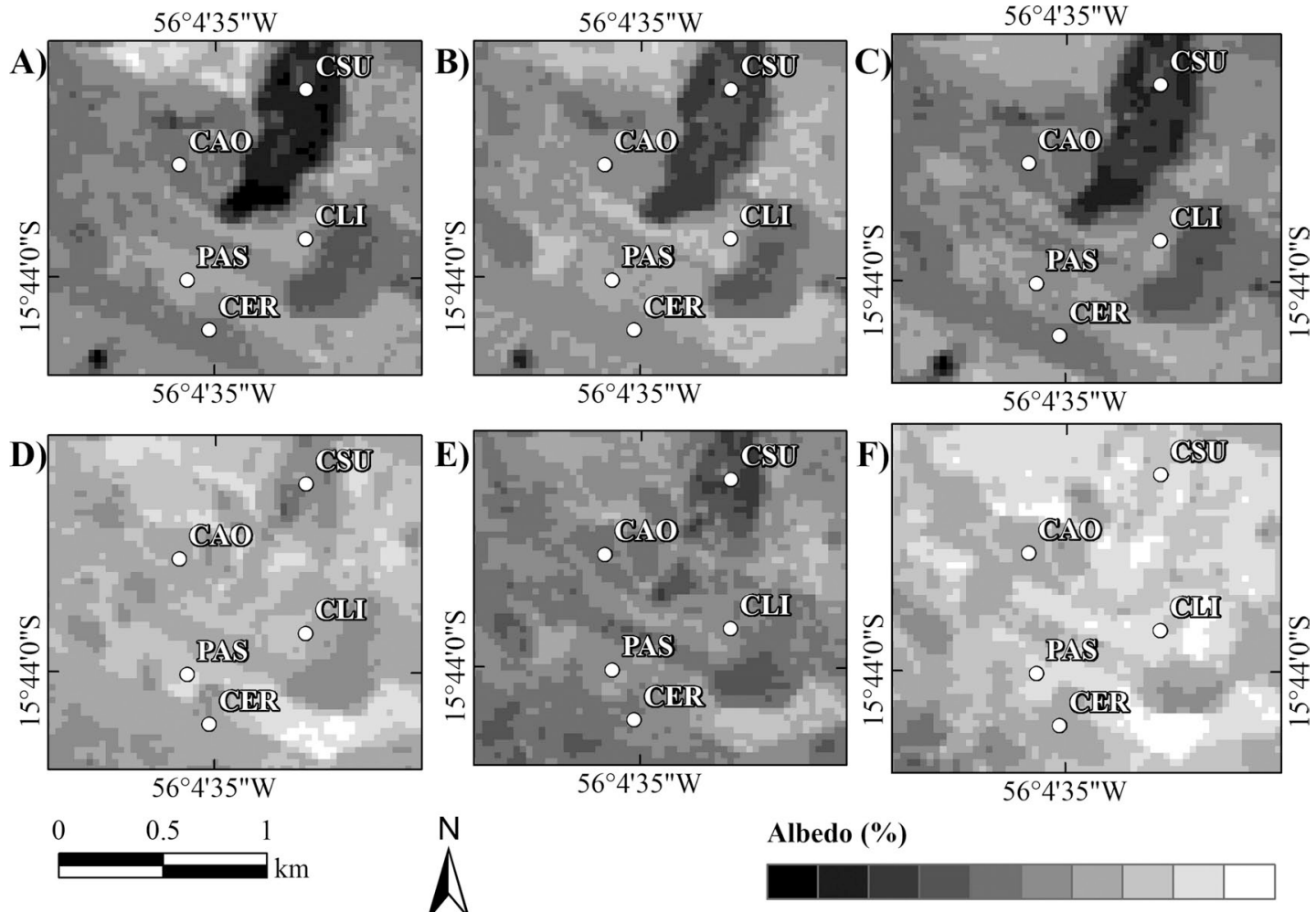

$56^{\circ} 45^{\prime \prime} \mathrm{W}$
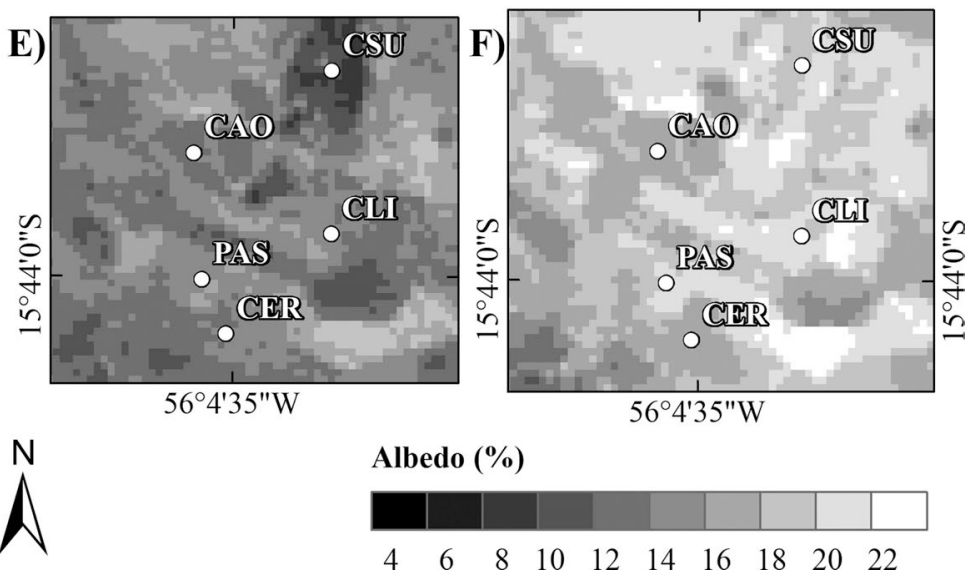

Figura 5 - Distribuição espacial do albedo da superfície ( $\alpha$ em Campo Limpo (CLI), Pastagem (PAS), Campo Sujo (CSU), Cerradão (CAO) e em Cerrado stricto sensu (CER), na Fazenda Miranda, no período chuvoso (A, B e C) e período seco (D, E e F), de 2009 a 2011.
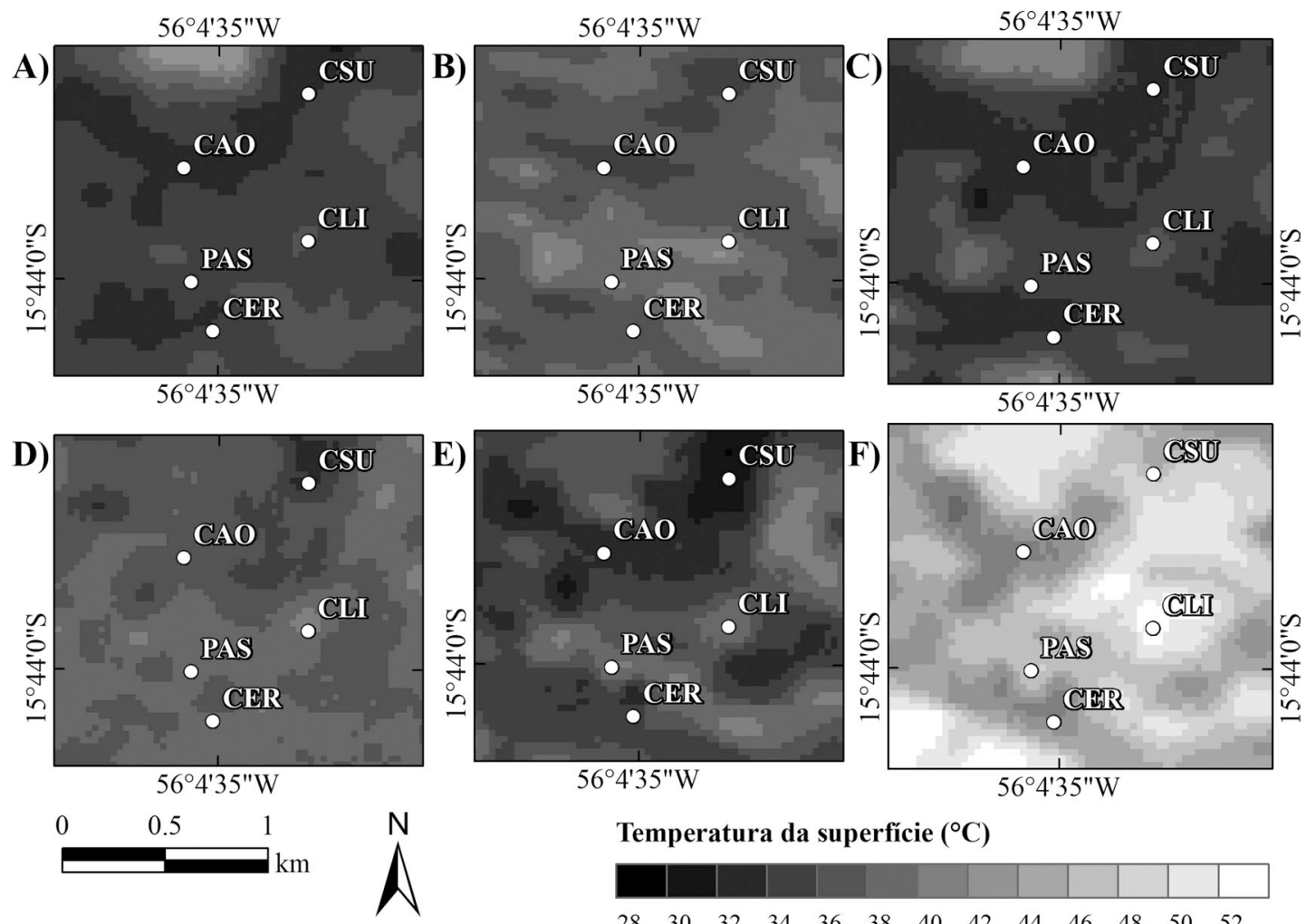

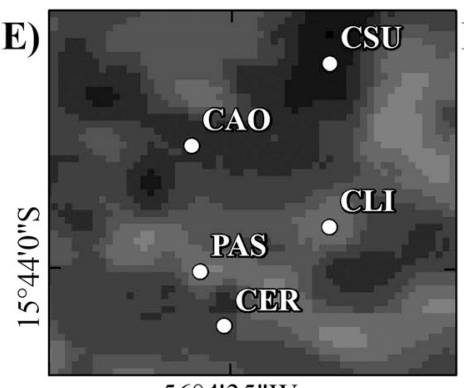

$56^{\circ} 4^{\prime} 35^{\prime \prime} \mathrm{W}$

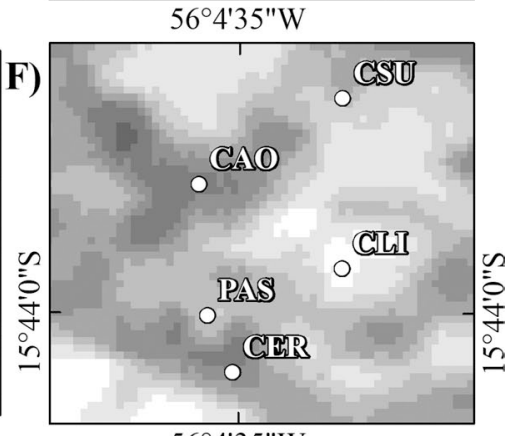

$56^{\circ} 4^{\prime} 35^{\prime \prime} \mathrm{W}$

Temperatura da superfície $\left({ }^{\circ} \mathrm{C}\right)$

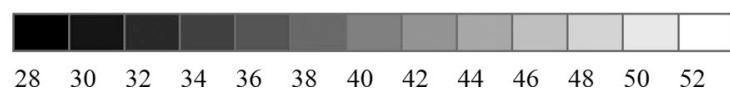

Figura 6 - Distribuição espacial da temperatura da superfície $\left(T_{s}\right)$ em Campo Limpo (CLI), Pastagem (PAS), Campo Sujo (CSU), Cerradão (CAO) e em cerrado stricto sensu (CER), na Fazenda Miranda, no período chuvoso (A, B e C) e período seco (D, E e F), de 2009 a 2011. 
maior que no CAO, e não diferiu no CSU, CER e CAO (Tabela 2).

A relação entre o $N D V I, \alpha$ e o $T_{s}$ se dá pelas relações diretas e indiretas com a disponibilidade de água na superfície que modifica as características óticas e termodinâmicas da superfície (Fausto et al., 2014; Fausto et al., 2016; Ivo et al., 2018). Áreas com baixa cobertura de vegetação são mais claras e refletem mais radiação solar global, enquanto áreas com vegetação densa capturam mais eficientemente a radiação solar que penetra no interior do dossel e não retornam para a atmosfera (Querino et al., 2016). Por outro lado, áreas com vegetação densa, geralmente, conseguem absorver água da superfície mais eficientemente que áreas com vegetação rasteira ou esparsa (Biudes et al., 2015). Essas áreas de vegetação densa, então, utilizam a radiação solar prioritariamente na forma de calor latente. Dessa forma, apresenta $T_{s}$ menor que áreas com vegetação rasteira ou esparsa que utilizam a radiação solar prioritariamente na forma de calor sensível (Angelini et al., 2017). O solo da região tem baixa capacidade de retenção de água e alta taxa de infiltração de água e, portanto, condiciona a utilização da energia disponível na forma de calor sensível, o que contribui para o aumento na $T_{s}$ no período seco (Fausto et al., 2014).
O $R n$ período chuvoso foi $15 \%$ menor que período seco (Fig. 8; Tabela 2). A heterogeneidade da superfície com variação do $N D V I, \alpha$ e o $T_{s}$ condicionaram variação do $R n$ na área de estudo. O Rn na PAS e no CLI foram $8 \%$ e $10 \%$ menores que o $\mathrm{CAO}$, mas não houve diferença do $R n$ no CSU, CER e CAO (Tabela 2).

Os resultados obtidos neste trabalho corroboram com outros estudos realizados no Cerrado. No município de Santo Antônio do Leverger-MT, o $R n$ no período chuvoso foi $24 \%$ maior que no período seco (Fausto et al., 2014). Nesse mesmo estudo, o $R n$ na pastagem foi $11 \%$ menor que na vegetação nativa. Em estudo realizado em área de reserva legal no município de Campo Novo do Parecis-MT, o $R n$ na área desmatada foi $10 \%$ menor que na reserva florestal, indicando o efeito da vegetação sobre o Rn (Martins et al., 2015). Padrão semelhante a esse estudo foi encontrado no bioma amazônico em Humaitá$\mathrm{AM}$, onde o $R n$ foi maior em área de vegetação nativa $\mathrm{e}$ menor em área antropizada (Silva et al., 2016). Enquanto a relação direta do $R n$ com a disponibilidade de água no solo também foi observada em experimentos na Bahia e na Paraíba (Borges et al., 2010; Di Pace et al., 2008).

Esse padrão se deu, pois, as áreas com superfícies com vegetação densa nativa do Cerrado possuem mais

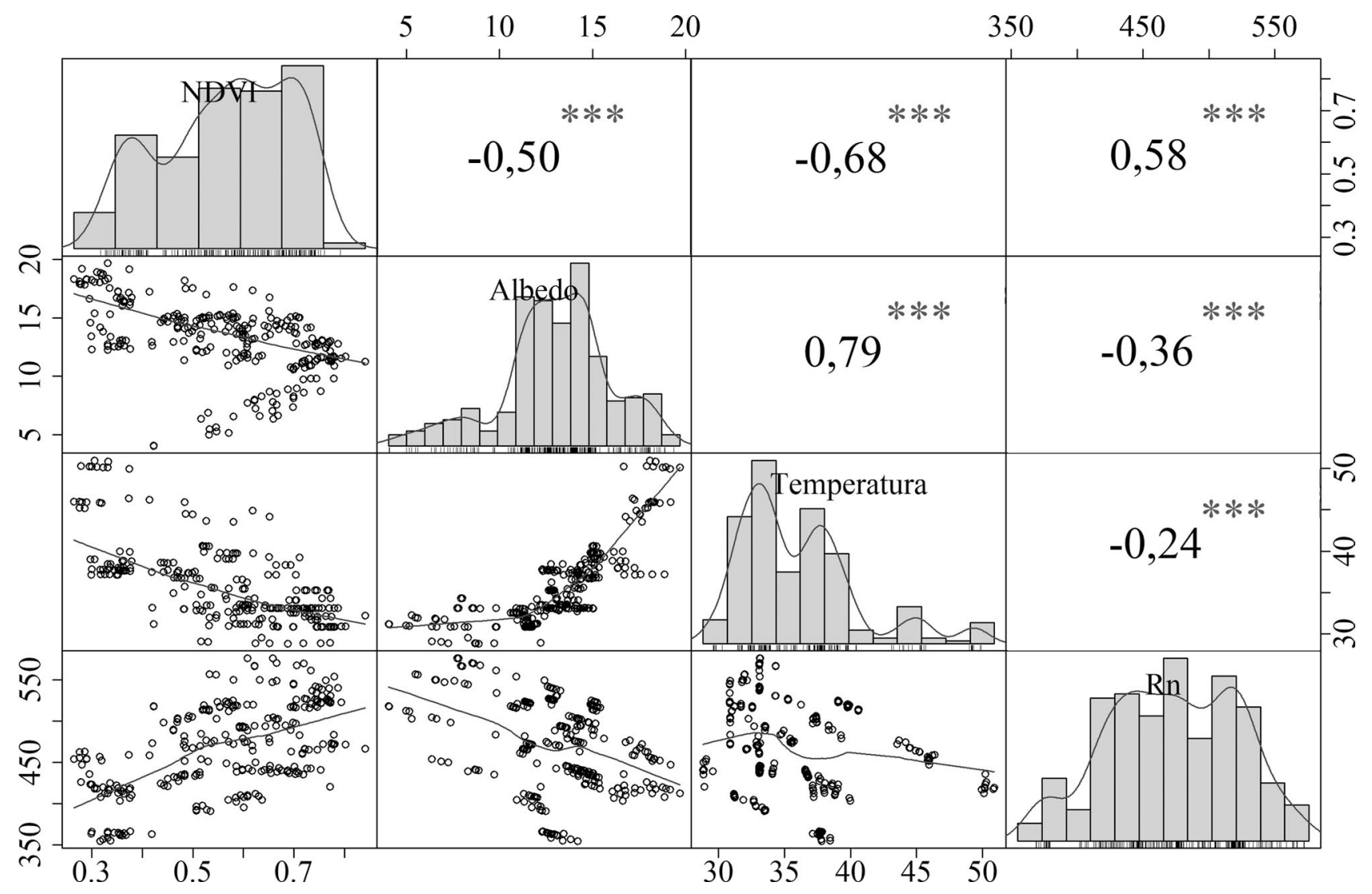

Figura 7 - Correlograma entre o $N D V I$, albedo da superfície, temperatura da superfície e o saldo de radiação, considerando o método de Spearman para o cálculo do coeficiente de correlação, com valor-p $<0,001$. 

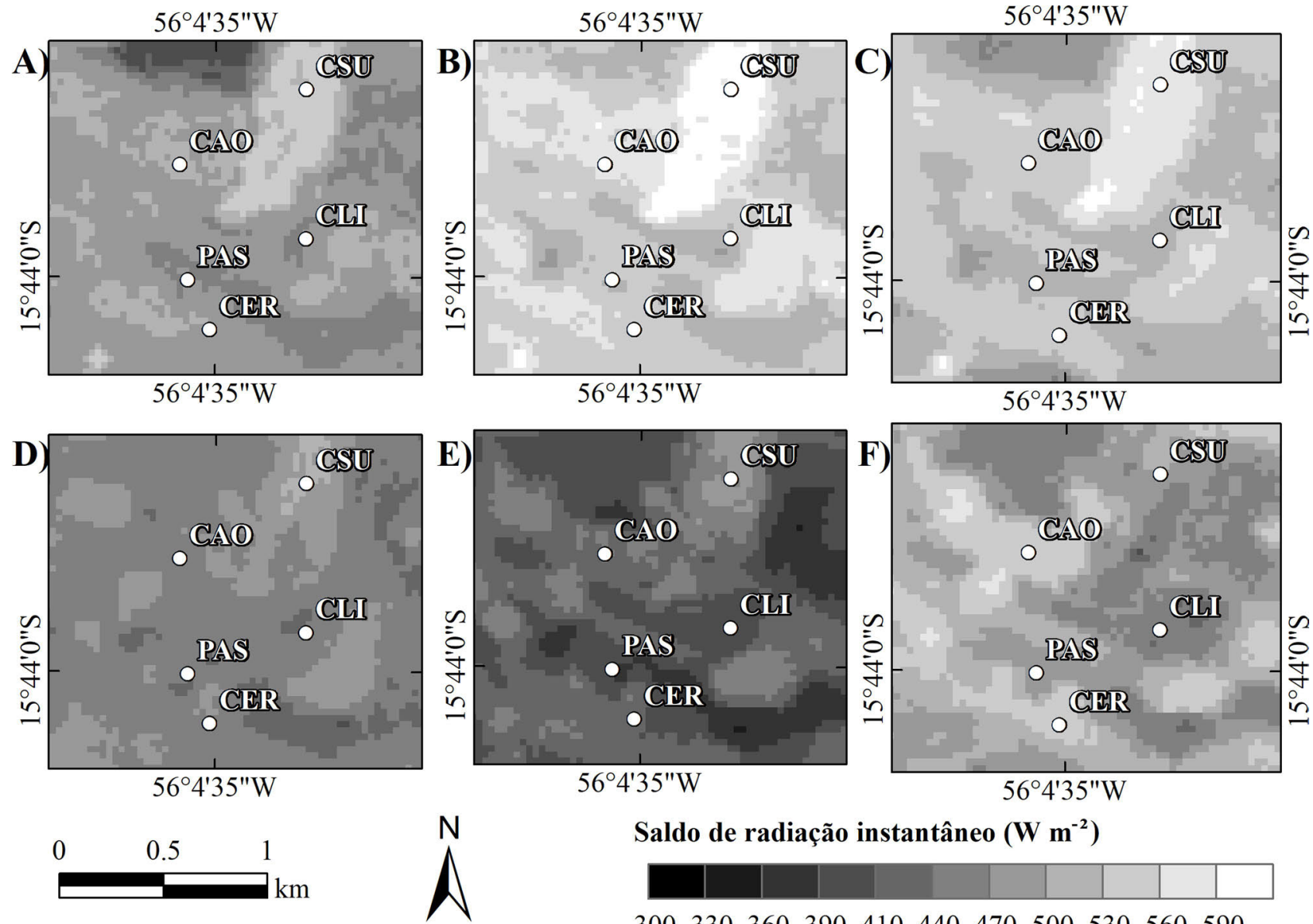

Saldo de radiação instantâneo $\left(W^{-2}\right)$

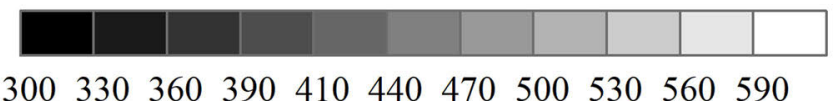

Figura 8 - Distribuição espacial do saldo de radiação (Rn) em Campo Limpo (CLI), Pastagem (PAS), Campo Sujo (CSU), Cerradão (CAO) e em Cerrado stricto sensu (CER), na Fazenda Miranda, de 2009 a 2011, nos períodos chuvoso (A, B e C) e período seco (D, E e F).

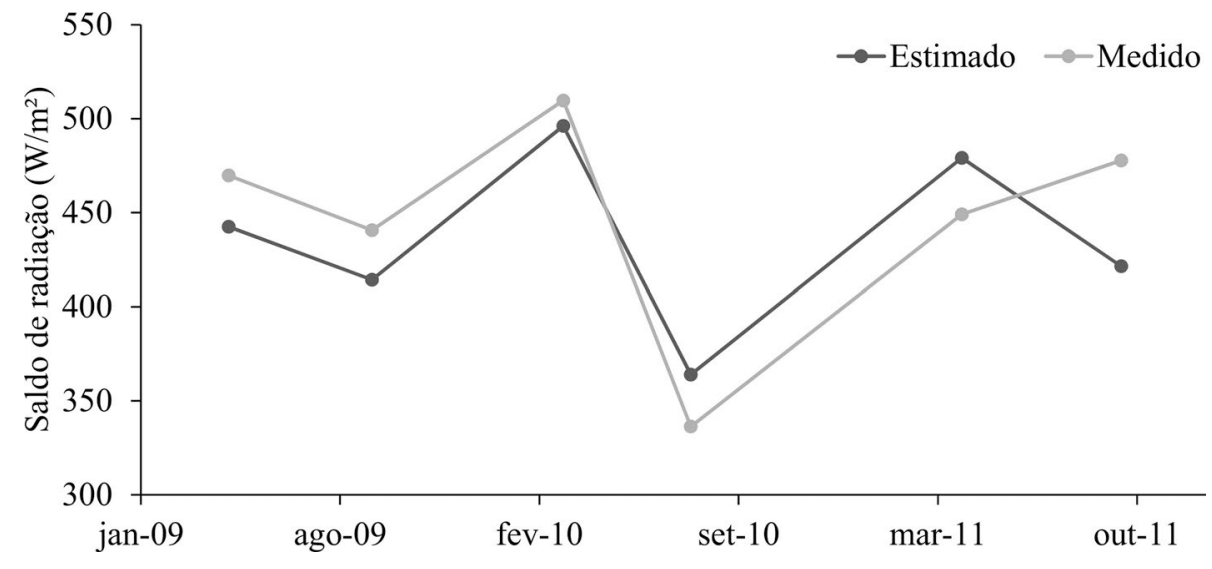

Figura 9 - Série temporal dos valores estimados e medidos do saldo de radiação (Rn) na Fazenda Miranda, em 2009, 2010 e 2011.

biomassa que superfícies antropizadas ou com vegetação rasteira (Martins et al., 2015; Fausto et al., 2016). Áreas com baixa cobertura vegetal ou solo exposto possuem maiores valores de $\alpha$ e $T_{s}$, que afetam os balanços de onda curta e longa, respectivamente (Fausto et al., 2014; Querino et al., 2017). Os maiores valores de $\alpha$ implicam numa maior reflexão da radiação solar global e maiores valores de $T_{s}$ implicam numa maior reemissão da radiação de onda longa pela superfície, diminuindo os balanços de onda curta e longa, respectivamente, e por conseguinte diminui o $R n$ da superfície (Fausto et al., 2016). 
O Rn estimado por sensoriamento remoto teve baixos erros em relação ao $R n$ medido $(E M A=10,93 \mathrm{~W}$ $\left.\mathrm{m}^{-2} ; R E Q M=32,86 \mathrm{~W} \mathrm{~m}^{-2} ; P M R E=6,87 \%\right)$, forte correlação $(\mathrm{r}=0,82$; valor-p $<0,001)$ e elevado de concordância $(d=0,89)$. O Rn no período chuvoso teve os menores erros associados à sua estimativa, com EMA de 3,53 W m-2, enquanto o Rn no período seco teve um EMA de $18,33 \mathrm{~W} \mathrm{~m}^{-2}$.

Os erros encontrados se devem principalmente à soma do erro instrumental associado as medidas do saldo de radiação $(2,5 \%)$ ao erro associado à própria obtenção das imagens pelo TM Landsat 5, pois o $R n$ estimado em cada pixel representa uma área de $30 \times 30 \mathrm{~m}$ e a medição na torre é pontual (Gusmão et al., 2012). O padrão dos erros encontrados nos períodos seco e chuvoso pode ser explicado pelo fato que no período seco ocorrem as maiores concentrações de micropartículas suspensas na atmosfera. Com isso, uma fração significativa da radiação solar é absorvida ou espalhada pela própria alta atmosfera, prejudicando as estimativas do balanço de radiação. No período chuvoso, a atmosfera apresenta menos micropartículas, favorecendo eventos de céu totalmente limpo que são favoráveis as estimativas por imagens de satélite (Palácios et al., 2014; Santos et al., 2016).

\section{Conclusões}

Os parâmetros biofísicos apresentaram variação sazonal, condicionados principalmente pela precipitação, com maiores valores de $N D V I$ e $R n$ e menores valores de $\alpha$ e $T_{S}$ durante o período chuvoso.

$\mathrm{O}$ estudo identificou padrões espaciais com maiores valores de $N D V I$ e $R n$ e menores valores de $\alpha$ e $T_{s}$ em locais com maior biomassa vegetal. Os maiores valores de $N D V I$ e Rn ocorreram nas áreas de Cerrado denso nativo e os maiores valores de $\alpha$ e $T_{s}$ ocorreram na área de pastagem.

O modelo de $R n$ utilizado neste estudo apresentou elevado desempenho com baixos erros e elevados índices de correlação e de concordância. Portanto, esse o modelo pode ser utilizado para estimar o $R n$ de superfícies semelhantes ao desse estudo.

\section{Agradecimentos}

A pesquisa foi apoiada pela Universidade Federal de Mato Grosso (UFMT), Programa de Pós-Graduação em Física Ambiental (PPGFA/IF/UFMT), Instituto Federal de Mato Grosso (IFMT), Conselho Nacional de Desenvolvimento Científico e Tecnológico (CNPq, processos $n^{\circ} 310879$ / 2017-5 e 305761/2018-8; Edital Universal 01/2016, processo $n^{\circ}$ 407463/2016-0) e Fundação de Amparo à Pesquisa do Estado de Mato Grosso (FAPEMAT - PRONEM 2014, processo $\mathrm{n}^{\circ} 561397 / 2014$ ).

\section{Referências}

ALLEN, R.G.; TASUMI, M.; TREZZA, R; WATERS, R.; BASTIAANSSEN, W. Advanced Training and user's Manual. Surface Energy Balance Algorithms for Land (SEBAL). Kimberly, Idaho, v. 1, 2002.

ANGELINI, L.P.; SILVA, P.C.B.S.; FAUSTO, M.A. MACHADO, N.G.; BIUDES, M.S. Balanço de energia nas condições de mudanças de uso do solo na região sul do estado de mato grosso. Revista Brasileira de Meteorologia, v. 32, n. 3, p. 353-363, 2017.

BARSI, J.A.; BARKER, J.L.; SCHOTT, J.R.; An atmospheric correction parameter calculator for a single thermal band earth-sensing instrument. Proc. of IEEE Int. Geoscience and Remote Sensing Symp., pp. 3014-3016, 2003.

BARSI, J.A.; SCHOTT, J.R.; PALLUCONI, F.D.; HOOK, S.J. Validation of a web-based atmospheric correction tool for single thermal band instruments. Proc. SPIE 5882, Earth Observing Systems X, p. 58820E, 2005.

BASTIAANSSEN, W.G.M.; NOORDMAN, E.J.M.; PELGRUM, H.; DAVIDS, G; THORESON, B.P.; ALLEN, R.G. SEBAL model with remotely sensed data to improve water resources management under actual field conditions. J. Irrig. Drain. Eng., v. 131, n. 1, p. 85-93, 2005.

BIUDES, M.S.; CAMPELO JÚNIOR, J.H.; NOGUEIRA, J.S.; SANCHES, L. Estimativa do balanço de energia em cambarazal e pastagem no norte do Pantanal pelo método da razão de bowen. Revista Brasileira de Meteorologia, v. 24, n. 2, p. 135-143, 2009.

BIUDES, M.S.; VOURLITIS, G.L.; MACHADO, N.G.; ARRUDA, P.H.Z.; NEVES, G.A.R.; LOBO, F.A.; NEALE C.M.U.; NOGUEIRA, J.S. Patterns of energy exchange for tropical ecosystems across a climate gradient in Mato Grosso, Brazil. Agricultural and Forest Meteorology, v. 202, n. 1, p. 112-124, 2015.

BORATTO, I.M.P.; GOMIDE, R.L. Aplicação dos índices de vegetação NDVI, SAVI e IAF na caracterização da cobertura vegetativa da região Norte de Minas Gerais. Anais XVI Simpósio Brasileiro de Sensoriamento Remoto SBSR, p. 7345-7352, 2013.

BORGES, V.P.; OLIVEIRA, A.S.; SILVA, B.B. Mapeamento e quantificação de de parâmetros biofísicos e radiação líquida em área de algodoeiro irrigado. Ciênc. Agrotec., v. 34, n. 2, p. 485-493, 2010

DANELICHEN, V.H.M.; BIUDES, M.S.; SOUZA, M.C.; MACHADO, N.G.; NOGUEIRA, J.S. Relations of vegetation and water indices to volumetric soil water content in the Pantanal of Mato Grosso, Brazil. Journal International Journal of Remote Sensing, v. 37, n. 18, p. 4261-4275, 2016.

DANELICHEN, V.H.M.; MACHADO, N.G.; SOUZA, M.C.; BIUDES, M.S. TRMM Satellite performance in estimating rainfall over the Midwest region of Brazil. Revista Brasileira de Climatologia, v. 9, n. 2, p. 22-31, 2013.

DANELICHEN, V.H.M.; VELASQUE, M.C.S.; MUSIS, C.R., MACHADO, N.G.; NOGUEIRA, J.S.; BIUDES, M.S. Estimativas de índice de área foliar de uma pastagem por sensoriamento remoto no Pantanal Mato-grossense. Ciência e Natura, v. 36, n. 3, p. 373-384, 2014.

DI PACE, F.T.; SILVA, B.B.; SILVA, V.P.R. Mapeamento do saldo de radiação com imagens Landsat 5 e modelo de ele- 
vação digital. Revista Brasileira de Irrigação Agrícola e Ambiental, v. 12, p. 385-392, 2008.

EFRON, B.; TIBSHIRANI, R. An Introduction to the Bootstrap. Chapman and Hall, London, 1993.

FAUSTO, M.A.; MACHADO, N.G.; NOGUEIRA, J.S.; BIUDES, M.S. Net radiation estimated by remote sensing in Cerrado areas in the Upper Paraguay River Basin. Journal of Applied Remote Sensing, v. 8, n.1, p.083541, 2014.

FAUSTO, M.A.; ANGELINI, L.P.; MARQUES, H.O.; SILVA FILHO, A.; MACHADO, N.G.; BIUDES, M.S. Impacto da alteração do uso do solo no saldo de radiação no Cerrado do sul de Mato Grosso. Rev. Ambient. Água, v. 11, n. 2, p. 350-361 2016 .

GOMES, H.B.; SILVA, B.B.; CAVALCANTI, E.P.; ROCHA, H.R. Balanço de radiação em diferentes biomas no estado de São Paulo mediante imagens Landsat 5. Geociências, v. 28, p. 153-164, 2009.

GUSMÃO, A.C.V.L.; SILVA, B.B.; MONTENEGRO, S.M.G.L.; GALVÍNCIO, J.D. Determinação do saldo radiativo na Ilha do Bananal, TO, com imagens orbitais. Revista Brasileira de Engenharia Agrícola e Ambiental, v. 16, n. 10, p. 1107-1114, 2012.

IDSO. S.B. "A set of equations for full spectrum and 8- to $14-\mu \mathrm{m}$ and 10.5 - to $12.5-\mu \mathrm{m}$ thermal radiation from cloudless skies". Water Res., v. 17, p. 295-304, 1981.

IVO, I.O.; BIUDES, M.S.; MACHADO, N.G.; PAVÃO, V.M.; Influência do desmatamento no índice de área foliar e temperatura da superfície no Cerrado mato-grossence. Revista Nativa, v. 6, n. 4, p. 364-369, 2018.

LIANG, S.; SHUEY, C.J.; RUSS, A.L.; FANG, H.; CHEN, M.; WALTHALL, C.L.; DAUGHTRY, C.S.T.; HUNT JR., R. Narrowband to broadband conversions of land surface albedo: II. Validation. Remote Sensing of Environment, v. 84, p. 25-44, 2002.

MACHADO, N.G.; BIUDES, M.S.; ANGELINI, L.P.; MÜTZENBERG, D.M.S.; NASSARDEN, D.C.S.; BILIO, R.S.; SILVA, T.J.A.; NEVES, G.A.R.; ARRUDA, P.H.Z.; NOGUEIRA, J.S. Sazonalidade do balanço de energia e evapotranspiração em área arbustiva alagável no Pantanal Mato-Grossense. Revista Brasileira de Meteorologia, v. 31, n. 1, p. 82-91, 2016.

MARCUZZO, F.F.N.; MELO, D.C.R. Distribuição espaço-temporal e sazonalidade das chuvas no estado do Mato Grosso. Revista Brasileira de Recursos Hídricos - RBRH, v. 16, n. 4, p. 157-167, 2011

MARTINS, A.L.; CUNHA, C.R.; PEREIRA, V.M.R.; DANELICHEN, V.H.M.; MACHADO, N.G.; LOBO, F.A.; MUSIS, C.R.; BIUDES M.S. Mudanças em índices biofísicos devido à alteração da cobertura do solo em área nativa de Cerrado em Mato Grosso. Ciência e Natura, v. 37 n. 4, p. 152-159, 2015.

PALÁCIOS, R.S.; SALLO, F.S.; PRADO, M.J.; MUSIS, C.R.; NOGUEIRA, J.S. Análise da profundidade ótica de aerossóis e coeficiente de angstrom no cerrado mato-grossense. Revista Brasileira de Climatologia, v. 14, p. 173, 2014.

PAVÃO, V.M; QUERINO, C.A.S.; BENEDITTI, C.A.; PAVÃO, L.L.; QUERINO, J.K.A.S.; MACHADO, N.G.; BIUDES, M.S. Temperatura e albedo da superfície por imagens TM Landsat 5 em diferentes usos do solo no sudoeste da Ama- zônia brasileira. Revista Brasileira de Climatologia, v. 16, p. 169-183, 2015.

PETERSON, B.G.; CARL, P. PerformanceAnalytics: Econometric Tools for Performance and Risk Analysis. R package version 1.5.2, 2018. Disponível em: https://CRAN.Rproject.org/package=PerformanceAnalytics.

QUERINO, C.A.S.; BENEDITTI, C.A.; MACHADO, N.G.; SILVA, M.J.G.; QUERINO, J.K.A.S.; SANTOS NETO, L.A.; BIUDES, M.S. Spatiotemporal NDVI, LAI, albedo, and surface temperature dynamics in the southwest of the Brazilian Amazon forest. J. Appl. Remote Sens., v. 10, v. 2, p. 026007, 2016.

QUERINO, C.A.S.; BIUDES, M.S.; MACHADO, N.G.; QUERINO, J.K.A.S.; NETO, L.A.S.; SILVA, M.J.G.; ARRUDA, P.H.Z.; NOGUEIRA, J.S. Balanço de ondas curtas sobre floresta sazonalmente alagável do Pantanal matogrossense. Revista Brasileira de Climatologia, v. 20, p. 252-266, 2017.

SALLO, F.S.; FRANÇA, M.S.; MORAIS, D.M.; RODRIGUES, R.; BIUDES, M.S. Estimativa de componentes do balanço de radiação em diferentes tipos de uso e cobertura do solo. Revista Ambiente \& Água, v. 9, n. 2, p. 347-358, 2014.

SANTOS, A.C.A.; FINGER, A.; NOGUEIRA, J.S.; CURADO, L.F.A.; PALÁCIOS, R.S.; PEREIRA, V.M.R. Análise da concentração e composição de aerossóis de queimadas no Pantanal Mato Grosso. Quim. Nova, v. 39, n. 8, p. 919924, 2016.

SILVA, L.C.; CUNHA, J.M.; MACHADO, N.G.; CAMPOS, M.C.C.; BIUDES, M.S. Estimativa do balanço de radiação por sensoriamento remoto de diferentes usos de solo no sudoeste da Amazônia brasileira. Soc. \& Nat., v. 24, n. 2, p. $135-143,2016$.

VALOR, E.; CASELLES, V. Mapping land surface emissivity from NDVI: Application to European, African, and South American areas. Remote Sensing of Environment, v. 57, p. $167-184,1996$.

VOURLITIS, G.L., LOBO, F.A.; LAWRENCE, S.; LUCENA, I.C.; BORGES JR., O.B.; DALMAGRO, H.J.; ORTIZ, C.E.R.; NOGUEIRA, J.S. Variations in stand structure and diversity along a soil fertility gradient in a Brazilian savanna (Cerrado) in southern Mato Grosso. Soil Sci. Soc. Am. J., v. 77, n. 4, p. 1370-1379, 2013.

WILLMOTT, C.J.; ACKLESON, S.G.; DAVIS, R.E.; FEDDEMA, J.J.; KLINK, K.M.; LEGATES, D.R.; O'DONNELL, J.; ROWE, C.M. Statistics for the evaluation and comparison of models. Journal of Geophysical Research, v. 90, n. C5, p. 8995-9005, 1985.

\section{Endereços de Internet}

GIOVANNI. National Aeronautics and Space Administration (NASA) Disponível em: <https://giovanni.gsfc.nasa.gov/ giovanni>, Acesso em 08/07/2018.

INMET. Instituto Nacional de Meteorologia. Disponível em: $<$ inmet.gov.br/portal/index.php? $\mathrm{r}=$ clima/normaisClimatologicas $>$, Acesso em 08/07/2018.

License information: This is an open-access article distributed under the terms of the Creative Commons Attribution License (type CC-BY), which permits unrestricted use, distribution and reproduction in any medium, provided the original article is properly cited. 